\title{
Characterization and evaluation of liver fibrosis grade in patients with chronic hepatitis B virus infection and normal transaminases
}

\author{
San Juan López Cristina', Casado Martín Marta', González Sánchez Mercedes', Porcel Martín Almudena', \\ Hernández Martínez Álvaro', Vega Sáenz Jose Luis' ${ }^{1}$ and Parrón Carreño Tesifón ${ }^{2}$ \\ 'Department of Digestive Diseases, Torrecárdenas Hospital, University of Almería, Almería; '2Department of Nursing, Physiotherapy \\ and Medicine, University of Almería, Almería, Spain
}

Backgrounds/Aims: The objective of our study was to determine the epidemiological, laboratory, and serological characteristics of patients with chronic hepatitis B virus (HBV) infection and normal transaminases. The study also aimed to evaluate liver damage by measuring the liver fibrosis (LF) grade and to identify possible factors associated with the presence of fibrosis.

Methods: A retrospective observational study was conducted in patients with chronic HBV infection and classified as inactive carriers or immune-tolerant. Epidemiological variables of age, sex, immigrant, alcohol consumption, and body mass index (BMI), as well as virological variables (HBV DNA) and transaminase level were collected throughout the follow-up. The LF grade was evaluated by transient elastography. The cutoff value for significant fibrosis (SF) was liver stiffness $\geq 7.9 \mathrm{kPa}$.

Results: A total of 214 patients were included in the analysis, and $62 \%$ of them had a BMI $\geq 25 \mathrm{~kg} / \mathrm{m}^{2}$. During follow-up, $4 \%$ of patients showed transaminase elevation ( $<1.5$ times normal). Most patients had a viral DNA level $<2,000 \mathrm{IU} / \mathrm{mL}(83 \%)$. Data on LF were available in 160 patients; of these, 14\% had SF, 9\% F3, and $6 \%$ F4. The variables associated with the presence of SF were transaminase alteration during follow-up, as $23 \%$ of patients with SF had elevated transaminases versus $3 \%$ of patients without $S F(P<0.005)$, and BMl, as the vast majority of patients with $\mathrm{SF}(88 \%)$ had a $\mathrm{BMI} \geq 25 \mathrm{~kg} / \mathrm{m}^{2}$ versus $56 \%$ of patients without SF $(P<0.05)$.

Conclusions: In patients with chronic HBV infection and normal transaminases, liver damage does not seem to be related to DNA levels, alcohol consumption, or immigrant status. SF seems to be associated with transaminase alteration during follow-up and elevated BMI. It is therefore recommended to measure LF grade with validated non-invasive methods in such patients. (Clin Mol Hepatol 2018;24:384-391)

Keywords: Chronic hepatitis B virus infection; Hepatitis B e Antigens; Liver fibrosis; Elastography

\footnotetext{
Abbreviations:

ALT, alanine aminotransferase; ALT TN, altered transaminases; AST, aspartate aminotransferase; BMl, body mass index; Cl, confidence interval; DNA, deoxyribonucleic acid; HBV, hepatitis B virus; HCV, hepatitis C virus; HIV, human immunodeficiency virus; IC, inactive carrier; $I Q R$, interquartile range; IT, immunetolerant; $\mathrm{kPa}$, kilopascales; LF, liver fibrosis; $\mathrm{LS}$, liver stiffness; OR, odds ratio; $\mathrm{SF}$ significant fibrosis; TE, transient elastography; VL HBV, viral load HBV; WHO, World Health Organization
}

\section{Corresponding author : San Juan López Cristina}

Department of Digestive Diseases, Torrecárdenas Hospital, University of Almería, Street Hermandad de Donantes de Sangre, s/n. Almería 04009, Spain Tel: +34-950-1-60-00, Fax: +34-950-1-61-08

E-mail: csanjuan379@gmail.com

http://orcid.org/0000-0001-6261-1593 
San Juan López Cristina, et al.

\section{INTRODUCTION}

Hepatitis B virus (HBV) infection is currently the most common cause of chronic hepatitis worldwide. The World Health Organization (WHO) estimates that about 2 billion people have had contact with the virus and more than 400 million people are hepatitis B surface antigen ( $\mathrm{HBsAg})$ carriers, ${ }^{1-5}$ representing $5 \%$ of the world population. ${ }^{6,7}$ It is estimated that more than 50 million new cases are diagnosed annually. ${ }^{8}$

Liver disease by HBV covers a wide clinical spectrum ranging from the inactive carrier (IC) state to chronic hepatitis, liver cirrhosis and hepatocellular carcinoma. ${ }^{5,7}$ It is a dynamic process whose natural history can be divided into different stages based on hepatitis B e antigen (HBeAg) state, HBV deoxyribonucleic acid (DNA) serum levels and transaminase levels; these different stages are not necessarily sequential nor do they occur in all patients. ${ }^{4,5,9}$

In the HBeAg-negative phases, most patients remain in a HBV carrier state known as IC. This phase is characterized by a low viral replication rate, persistently normal transaminases, and minimal or no necroinflammatory activity, i.e., minimal or no liver damage. ${ }^{5,710,11}$ However, it is true that some studies suggest that some patients in this phase may have a high viral load and significant histological liver damage. ${ }^{3,12,13}$ In the HBeAg-positive phases, a large number of patients remain for many years in the immunetolerant (IT) state, characterized by normal transaminase levels and also classically associated with minimal or no liver damage.

There are currently few available studies evaluating the degree of liver damage in this type of patients, IC or IT, because until recently estimation of the degree of liver damage was based on histological analysis of the sample obtained in a liver biopsy, an invasive technique not without complications, ${ }^{14-19}$ which has hindered the conduct of studies in this type of patients with a low risk of liver damage.

The introduction of transient elastography (TE) has greatly improved evaluation of liver damage of different etiologies, since it is able to estimate liver fibrosis (LF) in a non-invasive and painless manner. ${ }^{15,17}$ This technique has shown an excellent ability to exclude the stage of hepatic cirrhosis and is good for identifying patients with different grades of fibrosis. In addition, its a technique that is easy to use, rapid, highly reproducible and reliable. ${ }^{20-23}$
These characteristics have made it the most used technique in current daily practice as an alternative to liver biopsy for evaluation of the degree of liver damage in patients with chronic infection of viral origin. ${ }^{5,15}$ Patients with chronic HBV infection with normal transaminase levels are also ideal patients for evaluating the LF grade using techniques such as $T E$, since in these patients there is no confounding factor from inflammatory activity expressed as elevated serum transaminases on laboratory tests and which can cause overestimation of LF. It is therefore the most accurate technique for evaluation of $L F$ in these patients. ${ }^{15,22,23}$

The objective of our study was to determine the epidemiological, laboratory and serological characteristics and LF grade of patients with chronic HBV infection and normal transaminases, and also to identify possible factors associated with the presence of significant liver fibrosis (SF).

\section{MATERIALS AND METHODS}

\section{Population and design}

We conducted a retrospective observational study in patients with chronic HBV infection and normal transaminases seen from 2006 to 2016 and with at least 1 year of follow-up in the Hepatology Clinics, Department of Gastroenterology, Torrecárdenas Hospital in Almería, Spain. Inclusion criteria were all patients 18 years or older monoinfected (hepatitis C virus [HCV] and human immunodeficiency virus [HIV] negative) with chronic HBV infection (HBsAg positive for at least 6 months) and with normal transaminases on at least 3 consecutive determinations in 9 months, according to normal values in our laboratory (aspartate transaminase $[\mathrm{AST}]<31$ and alanine transaminase $[\mathrm{ALT}]<32$ ). Patients with $\mathrm{HBV}$ infection and antiviral treatment and those who did not meet the inclusion criteria were excluded. None of our patients had history of descompensated cirrhosis or hepatocellular carcinoma, and all of them had normal liver function.

We defined IC patients as HBeAg-negative patients with persistently normal transaminases and IT patients as HBeAg-positive patients with normal transaminases. 


\section{Variables}

The following epidemiological variables: age, sex, immigrant, alcohol consumption and body mass index (BMI), and virological variables: HBV DNA and transaminase levels, were collected throughout the follow-up. We do not have the HBV genotype done.

We considered significant alcohol consumption as a daily intake above $20-40$ grams in women and above $40-60$ grams in men. The immigrant population mainly came from the north of África and Rumania.

BMI was classified as: normal weight (BMI $\left.<25 \mathrm{~kg} / \mathrm{m}^{2}\right)$, overweight (BMI $\left.25-30 \mathrm{~kg} / \mathrm{m}^{2}\right)$ and obese $\left(\mathrm{BMI} \geq 30 \mathrm{~kg} / \mathrm{m}^{2}\right)$. Hepatic steatosis data was assessed by ultrasonography.

We considered transaminase alteration the value of transaminases less than or equal to 1.5 times de normal value (AST $<31$ and ALT <32).

None of our patients had liver biopsy data; We evaluated the LF grade using TE (Fibroscan ${ }^{\circledR}$ Echosense, Paris, France). Liver stiffness (LS) was expressed in kilopascals (KPa). All studies were carried out by experienced operators. To be considered a reliable measurement, at least 10 valid measurements were required, a success rate greater than $60 \%$ and an interquartile range $<30 \%$ of the final stiffness value. ${ }^{24}$

SF was considered as LS values $\geq 7.9 \mathrm{kPa}$, grade 3 fibrosis (F3) as $L S$ values $\geq 8.8 \mathrm{kPa}$ and grade 4 fibrosis (F4), compatible with cirrhosis, as $L S$ values $\geq 11.7 \mathrm{KPa}^{25}$

Using dual cut-off values, we considered a liver stiffness value $<6.2 \mathrm{kPa}$ as absence of $L F$, between 6.2-9.4 $\mathrm{kPa}$ as a grey or transition zone, $\geq 9.4-12 \mathrm{kPa}$ as severe $\mathrm{LF}$, and a liver stiffness value $\geq 13.1 \mathrm{kPa}$ was considered F4, compatible with cirrhosis. ${ }^{26}$

\section{Statistical analysis}

The quantitative variables defined in this study were described as mean and standard deviation. Categorical variables were described as absolute numbers and percentages.

Fisher's exact test was used for categorical variables in the statistical analysis. A multivariate logistic regression model was constructed to establish associations between the different independent variables and the dependent variable (liver fibrosis $<7.9 \mathrm{kPa}$ versus liver fibrosis $\geq 7.9 \mathrm{kPa}$ ). The model was adjusted for those variables found statistically significant and variables with high clinical or diagnostic significance. Ninety-five percent confidence intervals $(\mathrm{Cl})$ were obtained.
Calculations were performed using the STATA version 12 statistical program (Stata, Madrid, Spain).

This study was approved by the Ethics Committee of our hospital.

\section{RESULTS}

Our study included a total of 214 patients, 208 classified as IC and 6 as IT. The mean age of our patients was $48 \pm 12$ years, and $60 \%$ (128) were men. Thirty percent (64) of patients were immigrants. Fourteen percent acknowledged significant alcohol consumption. BMI data were available in 145 patients, of which $38 \%$ had a BMl $<25,41 \%$ between 25 and 30 , and $21 \% \geq 30 \mathrm{~kg} / \mathrm{m}^{2}$. The mean BMI was $27 \pm 5 \mathrm{~kg} / \mathrm{m}^{2}$.

Transaminase data during follow-up were available in 191 patients. Of these, the majority (96\%) had normal transaminase levels during follow-up and only $4 \%$ showed altered transaminases during follow-up.

Viral load data were available in 180 patients. The mean viral load of IC patients was 1,339 $\pm 4,241 \mathrm{IU} / \mathrm{mL}$; the majority, $154 \mathrm{pa}$ tients (85\%), had HBV viral load levels less than 2,000 UI/mL, 24 (14\%) had a level between 2,000 and 20,000 IU/mL, and 2 patients (1\%) had a level $\geq 20,000 \mathrm{IU} / \mathrm{mL}$. IT patients had a mean viral load of $9.40 \pm 9.52$ million $\mathrm{IU} / \mathrm{mL}$.

The main epidemiological characteristics of the patients are summarized in Table 1.

LF data were available in 160 patients (74\%). TE could not be performed in 48 patients (23\%) due to loss to follow-up and in 6 patients (3\%) whose obesity prevented obtaining a valid measurement of LS.

Mean LS was $6.3 \pm 5.8 \mathrm{kPa}$. The analysis of the different LF grades showed that 22 patients had SF (14\%), 14 patients (9\%) had F3, and 10 patients (6\%) had a LF grade compatible with cirrhosis (F4).

If we use dual cutoff points, 101 patients did not have SF (63\%), 47 had LF in the grey zone (29\%), of which $3(2 \%)$ had data indicative of severe fibrosis and 9 had a LS compatible with cirrhosis (5\%).

Among patients with TE done, abdominal ultrasonography was available in 150 patients (72\%). In this group of patients, the general prevalence of fatty liver was 27\% (40 patients), moreover, when we analyse those patients with high BMI, 16 patients (27\%) with BMI $25-30 \mathrm{~kg} / \mathrm{m}^{2}$, and 13 patients (43\%) with BMI $>30 \mathrm{~kg} / \mathrm{m}^{2}$ had hepatic steatosis.

When we investigated the patients with fatty liver in the ultra- 
San Juan López Cristina, et al. Liver fibrosis grade in chronic HBV with normal transaminases

Table 1. Main characteristics of the sample

\begin{tabular}{lc}
\hline Patient characteristics & Total sample $(\mathbf{n}=\mathbf{2 1 4})$ \\
\hline Mean age (years) & $48 \pm 12$ \\
$<55$ years & $156(73)$ \\
$\geq 55$ years & $58(27)$ \\
Sex $(\mathrm{n}, \%)$ & \\
Male & $128(60)$ \\
Female & $86(40)$ \\
Immigrants $(\mathrm{n}, \%)$ & $64(30)$ \\
Alcohol intake $(\mathrm{n}, \%)$ & $31(14)$ \\
Mean BMI (kg/m $\left.{ }^{2}\right)(\mathrm{n}=145)$ & $27 \pm 5.41$ \\
$<25$ & $55(38)$ \\
$\geq 25$ & $90(62)$ \\
Transaminases $(\mathrm{n}=191)$ & \\
Unaltered & $183(96)$ \\
Altered & $8(4)$ \\
Mean HBV viral load in IC IU/mL $(\mathrm{n}=180)$ & $1,338 \pm 4,241$ \\
$<2,000$ & $154(86)$ \\
$2,000-20,000$ & $24(13)$ \\
$\geq 20,000$ & $2(1)$ \\
\hline
\end{tabular}

Values are presented as mean \pm SD or $n(\%)$

$B M I$, body mass index; HBV, hepatitis B virus; IC, inactive carriers.

sonography, 25 of them (62\%) had LF grade less than $7.9 \mathrm{kPa}$, and 15 patients (28\%) had LF more than $7.9 \mathrm{kPa}$.

The possible variables associated with the presence of SF were analysed. The variables studied were immigrant status, age stratified in 2 groups ( $<55$ years and $\geq 55$ years), sex, BMI grouped in $<25$ and $\mathrm{BMI} \geq 25 \mathrm{~kg} / \mathrm{m}^{2}$, alcohol consumption, viral load $(<2,000$, 2,000-20,000 and $\geq 20,000 \mathrm{lU} / \mathrm{mL}$ ), and transaminase elevation during the follow-up.

In the bivariate analysis, we found no association between the presence of SF and age, sex, immigrant status or alcohol consumption. With regard to viral load in patients classified as IC, we also found no association between the presence of LF and viral DNA.

The variables possibly associated with SF were BMI and transaminase elevation during the follow-up. Thus, $88 \%$ of patients with SF had a BMI $\geq 25 \mathrm{~kg} / \mathrm{m}^{2}$, compared to $5 \%$ of patients without SF $(P=0.01)$. If we consider patients with advanced fibrosis, $100 \%$ of patients with $\mathrm{F} 3$ had a BMI $\geq 25 \mathrm{~kg} / \mathrm{m}^{2}$, compared to $56 \%$ in patients with a LS less than $8.8 \mathrm{kPa}(P<0.05)$.

With regard to elevated transaminase levels during follow-up, $23 \%$ of patients with SF showed transaminase elevation, com- pared to $4 \%$ in patients without SF $(P=0.005)$. If we take a cutoff value for liver stiffness of $8.8 \mathrm{kPa}$, i.e., advanced fibrosis, $36 \%$ of patients belonging to this category showed transaminase elevation during follow-up, compared to $3 \%$ in patients without advanced fibrosis $(P<0.01)$. If we consider a cutoff value for liver stiffness of $11.7 \mathrm{kPa}$ (F4), $40 \%$ of these patients showed transaminase elevation during follow-up, compared to $4 \%$ of patients with data not compatible with grade 4 fibrosis $(P=0.01)$ (Table 2).

The multivariate regression analysis showed that having a BMI $\geq 25 \mathrm{~kg} / \mathrm{m}^{2}$ (odds ratio [OR]: 5.02, Cl [1.90, 13.20]), having an abnormal transaminase value during follow-up (OR: 9.37, Cl [1.37, 63.86]) and being male (OR: 3.54, $\mathrm{Cl}[0.91,13.69])$ increases the risk of having SF (although the latter was not statistically significant, it showed a trend towards this). In addition, each year of increase in age increased by 1.07 the risk of having a fibroscan LS measurement above the established cutoff point (7.9 kPa) (Cl $[1.01,1.13])$ (Table 3).

\section{DISCUSSION}

Classically, patients with chronic HBV infection and normal transaminase have been considered as patients without liver damage. However, there are few data objectively evaluating the presence of liver damage in this type of patients due to the need until recently of performing a liver biopsy to determine the degree of associated liver damage, this being an invasive technique not without risks.

A recent review of articles evaluating the degree of histological liver damage in patients classified as IC revealed that SF is rare in this type of patients, with an estimated $10 \%$ prevalence of moderate $\mathrm{LF}^{3}$ although some studies showed a prevalence of SF of up to $20 \%$. $^{27}$

The introduction in recent years of non-invasive methods to estimate the degree of liver damage by determination of LS has made it possible to approximate the degree of liver damage in these patients.

Our study evaluated LF grade by TE in a total of 160 patients with chronic HBV infection and normal transaminases, which is one of the largest series analysing the grade of liver damage in this type of patients. The results of our study show that at least $14 \%$ of patients considered IC or IT may have significant liver fibrosis taking as a cutoff value $7.9 \mathrm{kPa}, 9 \%$ have grade 3 fibrosis and up to $6 \%$ have data compatible with advanced fibrosis (F4). When we used dual cutoff values as proposed by Viganò et al. ${ }^{26}$, 


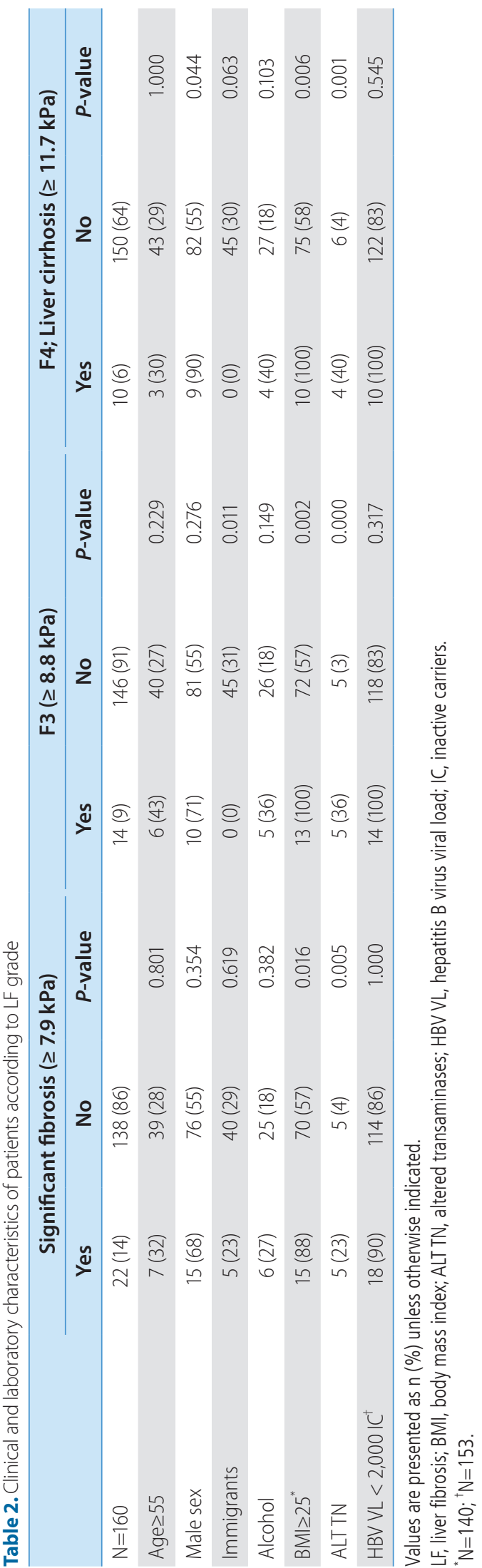

Table 3. Factors associated with significant liver fibrosis" Multivariate logistic regression model

\begin{tabular}{lccc}
\hline Variables & OR & $\mathbf{9 5 \%} \mathbf{C l}$ & $\boldsymbol{P}$-value \\
\hline BMI $\geq 25$ & 5.02 & $1.90-13.20$ & 0.001 \\
ALT TN & 9.37 & $1.37-63.86$ & 0.022 \\
Male sex & 3.54 & $0.91-13.69$ & 0.067 \\
Age & 1.07 & $1.01-1.13$ & 0.033 \\
\hline
\end{tabular}

$\mathrm{OR}$, odds ratio; $\mathrm{Cl}$, confidence interval; BMI, body mass index; ALT TN, altered transaminases.

"Fibrosis $\geq 7.9 \mathrm{kPa}$.

$23 \%$ of our patients had SF ( $\geq 6.2$ and $<9.4 \mathrm{kPa}$ ) with a rate of advanced fibrosis compatible with cirrhosis (F4) of $5 \%$. These data are similar to those published in a study carried out in 96 patients in whom the prevalence of SF was $25 \%$ and the prevalence of advanced fibrosis compatible with cirrhosis in IC patients was $6-7 \%{ }^{2,28-30}$ It therefore seems recommendable to evaluate liver damage by non-invasive methods such as TE in all patients classified as IC or IT.

This study allowed assessment of the different demographic and virological characteristics in a total of 214 patients with chronic HBV infection and normal transaminases. This analysis yielded similar data to those published in other series carried out in a similar setting to ours; predominance of male $\operatorname{sex}^{2,13}$ and a mean patient age of 47 years. ${ }^{30-32}$ More than half of our patients had a BMI $\geq 25 \mathrm{~kg} / \mathrm{m}^{2}$ and $21 \%$ had obesity. A third of our series corresponds to the immigrant population, revealing the increase in HBV infection in Spain in the last decades due to the arrival of immigrants from areas of high or intermediate prevalence, ${ }^{2,33,34}$ which reflects the importance of performing screening for this infection, especially in patients from areas with high endemicity. ${ }^{33,34}$

It should be noted that even though most of the patients classified as IC had a viral load $<2,000 \mathrm{IU} / \mathrm{mL}$ or negative, ${ }^{2} 14 \%$ of patients in our series had a viral load $>2,000 \mathrm{IU} / \mathrm{mL}$. This may be due to improper classification of patients or patients with progression from the IC stage to chronic hepatitis, though it is true that our analysis could not determine a higher grade of LF in patients with higher viral load, unlike other studies. ${ }^{3,35}$

The majority of the patients in our study (96\%) had normal transaminase levels at diagnosis and during follow-up, and only a small percentage showed minimal elevations above normal values, findings which are in agreement with those of other current publications in our setting. ${ }^{32,36}$ There are studies reporting that patients with normal transaminases at diagnosis have an up to $15-20 \%$ increased risk of showing alteration in these values dur- 
San Juan López Cristina, et al. Liver fibrosis grade in chronic HBV with normal transaminases

ing the first year of follow-up, ${ }^{3,37,38}$ with the risk decreasing after 3 years of follow-up. ${ }^{2,38,39}$

One of the objectives of our study was to evaluate possible variables that might be associated with the presence of SF in patients with chronic HBV infection and normal transaminases. According to the results of our analysis, SF does not seem to be related to viral DNA levels, age, sex, immigrant status or alcohol consumption. However, and this is one of the most relevant findings of our study, SF was associated with two variables, BMI and transaminase elevation during the follow-up. The results of the multivariate analysis showed that having a BMI $\geq 25 \mathrm{~kg} / \mathrm{m}^{2}$, having elevated transaminases during the follow-up, or being male increased the risk of having SF.

To date, there are few studies analysing the variables that may be associated with the presence of liver fibrosis in patients with chronic HBV infection.

We have data showing that obesity and metabolic syndrome are associated with an increased likelihood of progression from chronic HBV hepatitis to cirrhosis and a lower rate of regression of cirrhosis after antiviral treatment. ${ }^{40,41}$

There are few data in IC patients, but a recent Spanish study carried out in 96 patients with chronic HBV infection and normal transaminases revealed that the different components of the metabolic syndrome such as central obesity, hyperglycaemia and hypertriglyceridemia are factors associated with the presence of SF in these patients, while highlighting that in the absence of metabolic syndrome SF is uncommon in these patients. ${ }^{28}$

Oliveri et $\mathrm{a}^{35}$, in a study with 68 patients considered IC, found that patients with a dysmetabolic profile (dyslipidaemia, diabetes mellitus and elevated BMI) have a higher grade of LS than patients without them.

In our study, SF was associated with BMI, so the majority of patients with SF were overweight $\left(\mathrm{BMI} \geq 25 \mathrm{~kg} / \mathrm{m}^{2}\right)$ and all patients with $\mathrm{F} 3$ or higher had a $\mathrm{BMI} \geq 25 \mathrm{~kg} / \mathrm{m}^{2}$. This association is probably related to the presence of steatohepatitis, although we do not know if it involves an HBV infection with greater progression due to the presence of associated steatosis or a non-alcoholic steatohepatitis with associated HBV infection. In these patients, histological analysis with liver biopsy might help to differentiate the two entities. In any case, this association could at least allow recommendation of weight loss in these patients.

Another of the variables associated in our study with the presence of SF in IC patients was transaminase elevation during the follow-up less than $1.5 \times$ normal. Thus, $23 \%, 36 \%$ and $40 \%$ of patients with elevated transaminases during the follow-up had SF,
F3 and F4, respectively. However, only a small number (3-4\%) of patients maintaining normal transaminase levels during the follow-up had SF. It is likely that these patients with elevated transaminases in the follow-up were patients improperly classified initially as IC or IT. In any case, it seems reasonable to maintain monitoring of transaminases throughout the follow-up, and in patients with minimal elevations to consider evaluation of the degree of liver damage with $T E$, and in patients with evidence of SF to perform histological evaluation by liver biopsy.

Our study has some limitations as despite the fact that all patients included had a follow-up of at least 1 year to ensure their IC or IT status, the study had a cross-sectional design and the association of various factors with the presence of SF was analysed at a specific time point. Moreover, in $26 \%$ of patients, TE could not be performed due to technical problems (obesity) or losses to follow-up. Another limitation is that the sample size of IT phase is too small to be representative.

The results of our study show that, although the presence of LF is uncommon in patients with chronic HBV infection and normal transaminases, there were data indicative of SF in more than $10 \%$, of advanced fibrosis in up to $8 \%$ and of grade 4 fibrosis in $6 \%$. The presence of SF is associated with obesity and transaminase elevation during the follow-up, and therefore we think it is recommendable to evaluate the grade of LF in patients classified as IC or IT with validated non-invasive methods such as TE, mainly in those with a $\mathrm{BMI} \geq 25 \mathrm{~kg} / \mathrm{m}^{2}$ or those with minimal transaminase elevations during the follow-up, and to perform liver biopsy in patients with data indicative of SF.

\section{Authors' contribution}

San Juan López Cristina, Casado Martín Marta and González Sánchez Mercedes have participated in the study concept and design, in the acquisition of data and then in the analysis and interpretation of them, and we have draft the manuscript.

Porcel Martín Almudena, Hernández Martínez Álvaro, Vega Sáenz Jose Luis, and Parrón Carreño Tesifón have participated in the revision of the manuscript for important intellectual content.

\section{Conflicts of Interest}

The authors have no conflicts to disclose. 


\section{REFERENCES}

1. Lai $C L$, Yuen MF. The natural history and treatment of chronic hepatitis B: a critical evaluation of standard treatment criteria and end points. Ann Intern Med 2007;147:58-61.

2. Guardiola Arévalo A, Gómez Rodríguez R, Romero Gutiérrez M, Gómez Moreno AZ, García Vela A, Sánchez Simón R, et al. Characteristics and course of chronic hepatitis $B$ e antigen-negative infection. Gastroenterol Hepatol 2017;40:59-69.

3. Papatheodoridis GV, Manolakopoulos S, Liaw YF, Lok A. Follow-up and indications for liver biopsy in $\mathrm{HBeAg-negative} \mathrm{chronic} \mathrm{hepatitis}$ $B$ virus infection with persistently normal ALT: a systematic review. J Hepatol 2002;57:196-202.

4. Hadziyannis SJ, Papatheodoridis GV. Hepatitis B e antigen-negative chronic hepatitis B: natural history and treatment. Semin Liver Dis 2006;26:130-141.

5. European Association for the Study of the Liver. EASL Clinical Practice Guidelines: management of chronic hepatitis B. J Hepatol 2009;50:227-242.

6. Hu KQ. Hepatitis B virus (HBV) infection in Asian and Pacific Islander Americans (APIAs): how can we do better for this special population? Am J Gastroenterol 2008;103:1824-1833.

7. Buti M, García-Samaniego J, Prieto M, Rodríguez M, Sánchez Tapias $J M$, Suárez $E$, et al. Consensus document of the Spanish Association for the Study of the Liver on the treatment of Hepatitis B infection (2012). Gastroenterol Hepatol 2012;35:512-528.

8. Perrillo R. Hepatitis B virus replication x time equals trouble. Gastroenterology 2006;130:989-991.

9. Gómez Rodríguez R, Guardiola Arévalo A, Gómez Moreno AZ, García Vela A, Gómez Hernando C, Rodríguez Merlo R, et al. Characteristics of patients with chronic hepatitis $B$ virus infection. Analysis of a series of 474 patients. Gastroenterol Hepatol 2013;36:243-253.

10. Martinot-Peignoux M, Boyer N, Colombat M, Akremi R, Pham BN, Ollivier $\mathrm{S}$, et al. Serum hepatitis $B$ virus DNA levels and liver histology in inactive HBsAg carriers. J Hepatol 2002;36:543-546.

11. Invernizzi F, Viganò $M$, Grossi $G$, Lampertico P. The prognosis and management of inactive HBV carriers. Liver Int 2016;36 Suppl 1:100-104.

12. Lin CL, Liao LY, Liu CJ, Yu MW, Chen PJ, Lai MY, et al. Hepatitis B viral factors in $\mathrm{HBeAg-negative} \mathrm{carriers} \mathrm{with} \mathrm{persistently} \mathrm{normal}$ serum alanine aminotransferase levels. Hepatology 2007;45:11931198.

13. Kumar M, Sarin SK, Hissar S, Pande C, Sakhuja P, Sharma BC, et al. Virologic and histologic features of chronic hepatitis B virus-infected asymptomatic patients with persistently normal ALT. Gastroenterology 2008;134:1376-1384.

14. Rockey DC, Caldwell SH, Goodman ZD, Nelson RC, Smith AD; American Association for the Study of Liver Diseases. Liver biopsy. Hepatology 2009;49:1017-1044.
15. Castellano G, Manzano ML. The value of FibroScan(R) in the followup of patients with chronic hepatitis $B$ virus infection without indication for treatment. Gastroenterol Hepatol 2014;37 Suppl 2:15-21.

16. Bravo AA, Sheth SG, Chopra S. Liver biopsy. N Engl J Med 2001;344:495-500.

17. Wong VW, Chan HL. Transient elastography. J Gastroenterol Hepatol 2010;25:1726-1731.

18. Castéra L, Nègre I, Samii K, Buffet C. Pain experienced during percutaneous liver biopsy. Hepatology 1999;30:1529-1530.

19. Castéra L, Nègre I, Samii K, Buffet C. Patient administered nitrous oxide/oxygen inhalation provides safe and effective analgesia for percutaneous liver biopsy: a randomized placebo-controlled trial. Am J Gastroenterol 2001;96:1553-1557.

20. Chan HL, Wong GL, Choi PC, Chan AW, Chim AM, Yiu KK, et al. Alanine aminotransferase based algorithms of liver stiffness measurement by transient elastography (Fibroscan) for liver fibrosis in chronic hepatitis B. J Viral Hepat 2009;16:36-44.

21. Wong GL, Wong VW, Choi PC, Chan AW, Chim AM, Yiu KK, et al. Evaluation of alanine transaminase and hepatitis $B$ virus DNA to predict liver cirrhosis in hepatitis $B$ e antigen negative chronic hepatitis B using transient elastography. Am J Gastroenterol 2008;103:30713081.

22. Wong GL, Wong VW, Choi PC, Chan AW, Chim AM, Yiu KK, et al. Clinical factors associated with liver stiffness in hepatitis $B$ e antigen-positive chronic hepatitis B patients. Clin Gastroenterol Hepatol 2009; 7:227-233.

23. Wong GL, Wong VW, Choi PC, Chan AW, Chim AM, Yiu KK, et al. On-treatment monitoring of liver fibrosis with transient elastography in chronic hepatitis B patients. Antivir Ther 2011;16:165-172.

24. Castéra L, Bernard PH, Le Bail B, Foucher J, Trimoulet P, Merrouche $W$, et al. Transient elastography and biomarkers for liver fibrosis assessment and follow-up of inactive hepatitis B carriers. Aliment Pharmacol Ther 2011;33:455-465.

25. Chon YE, Choi EH, Song KJ, Park JY, Kim DY, Han KH, et al. Performance of transient elastography for the staging of liver fibrosis in patients with chronic hepatitis B: a meta-analysis. PLoS One 2012;7:e44930.

26. Viganò $M$, Paggi S, Lampertico P, Fraquelli M, Massironi S, Ronchi $\mathrm{G}$, et al. Dual cut-off transient elastography to assess liver fibrosis in chronic hepatitis B: a cohort study with internal validation. Aliment Pharmacol Ther 2011;34:353-362.

27. Fateen AA, Shahin RY, Farres MN, Eldeeb MA, Amer HA. Assessment of hepatic fibrosis and necroinflammation among inactive HBsAg carriers in Egypt. Ann Hepatol 2012;11:464-470.

28. Mena Á, Pedreira JD, Castro Á, López S, Vázquez P, Poveda E. Metabolic syndrome association with fibrosis development in chronic hepatitis B virus inactive carriers. J Gastroenterol Hepatol 2014;29:173-178. 
San Juan López Cristina, et al. Liver fibrosis grade in chronic HBV with normal transaminases

29. Wong GL, Chan HL, Yu Z, Chan HY, Tse CH, Wong VW. Liver fibrosis progression is uncommon in patients with inactive chronic hepatitis B: a prospective cohort study with paired transient elastography examination. J Gastroenterol Hepatol 2013;28:1842-1848.

30. Lin SY, Chang ET, So SK. Why we should routinely screen Asian American adults for hepatitis $B$ : a cross sectional study of Asians in California. Hepatology 2007;46:1034-1040.

31. Cadranel JF, Lahmek P, Causse X, Bellaiche G, Bettan L, Fontanges $T$, et al. Epidemiology of chronic hepatitis $B$ infection in France: risk factors for significant fibrosis--results of a nationwide survey. Aliment Pharmacol Ther 2007;26:565-576.

32. Poves-Martínez E, del Pozo-Prieto D, Costero-Pastor B, BorregoRodríguez G, Beceiro-Pedroño I, Sanz-García C, et al. Diagnostic incidence of the presence of positive HBsAg: epidemiologic, clinical, and virological characteristics. Rev Esp Enferm Dig 2012;104:10-15.

33. Fabris P, Baldo V, Baldovin T, Bellotto E, Rassu M, Trivello R, et al. Changing epidemiology of HCV and HBV infections in Northern Italy: a survey in the general population. J Clin Gastroenterol 2008:42:527-532.

34. Weinbaum CM, Williams I, Mast EE, Wang SA, Finelli L, Wasley A, et al. Recommendations for identification and public health management of persons with chronic hepatitis B virus infection. MMWR Recomm Rep 2008;57(RR-8):1-20.

35. Oliveri F, Coco B, Ciccorossi P, Colombatto P, Romagnoli V, Cherubini $B$, et al. Liver stiffness in the hepatitis $B$ virus carrier: a non-invasive marker of liver disease influenced by the pattern of transaminases.
World J Gastroenterol 2008;14:6154-6162.

36. Solá R, Cruz De Castro E, Hombrados M, Planas R, Coll S, Jardí R, et al. Prevalence of hepatitis $B$ and hepatitis $C$ viruses in different counties of Catalonia, Spain: cross-sectional study. Med Clin (Barc) 2002;22:90-95.

37. Papatheodoridis GV, Manesis EK, Manolakopoulos S, Elefsiniotis IS, Goulis J, Giannousis J, et al. Is there a meaningful serum hepatitis $B$ virus DNA cutoff level for therapeutic decisions in hepatitis $B$ e antigen-negative chronic hepatitis B virus infection? Hepatology 2008:48:1451-1459.

38. Papatheodoridis GV, Chrysanthos N, Hadziyannis E, Cholongitas E, Manesis EK. Longitudinal changes in serum HBV DNA levels and predictors of progression during the natural course of HBeAg-negative chronic hepatitis B virus infection. J Viral Hepat 2008;15:434441.

39. Ikeda K, Arase Y, Saitoh S, Kobayashi M, Someya T, Hosaka T, et al. Long-term outcome of HBV carriers with negative $\mathrm{HBe}$ antigen and normal aminotransferase. Am J Med 2006;119:977-985.

40. Wong GL, Wong VW, Choi PC, Chan AW, Chim AM, Yiu KK, et al. Metabolic syndrome increases the risk of liver cirrhosis in chronic hepatitis B. Gut 2009;58:111-117.

41. Marcellin P, Gane E, Buti M, Afdhal N, Sievert W, Jacobson IM, et al. Regression of cirrhosis during treatment with tenofovir disoproxil fumarate for chronic hepatitis B: a 5-year open-label follow-up study. Lancet 2013;381:468-475. 